Conclusion Distal middle cerebral artery thrombectomy with stent-retriever devices is achievable and can be safe and technically effective. Randomized controlled trials have not been performed to determine if thrombectomy in or distal to the M2-3 junction is more beneficial than other techniques, such as aspiration thrombectomy, intravenous thrombolysis, or maximum medical therapy.

Disclosures B. Donegan: None. J. Loeb: None. C. Martin: None. W. Holloway: None. J. Halpin: None. N. Akhtar: None.

\section{E-130 INCIDENCE AND OUTCOMES OF LARGE VESSEL OCCLUSION STROKE AFTER CARDIAC SURGERY AT A MAJOR ACADEMIC MEDICAL CENTER}

'D Wilkinson*, 'S Koduri, ${ }^{2} \mathrm{~J}$ Burke, ${ }^{3} \mathrm{~J}$ Gemmete, ${ }^{3} \mathrm{~N}$ Chaudhary, ${ }^{4} \mathrm{H}$ Patel, ${ }^{1} \mathrm{~A}$ Pandey. ${ }^{1}$ Neurosurgery, University of Michigan, Ann Arbor, Ml; ${ }^{2}$ Neurology, University of Michigan, Ann Arbor, Ml; ${ }^{3}$ Radiology, University of Michigan, Ann Arbor, Ml; ${ }^{4}$ Cardiac Surgery, University of Michigan, Ann Arbor, MI

\subsection{6/neurintsurg-2019-SNIS.205}

Background and purpose Stroke is one of the most feared complications of cardiac surgery. Modern stent-retrieval techniques provide effective treatment for large vessel occlusive strokes. The purpose of this study was to 1) report the incidence of large vessel occlusive stroke after cardiac surgery at a large academic center, and 2) describe outcomes after postoperative large vessel occlusive strokes (LVOs) associated with cardiac surgery.

Methods All patients experiencing stroke within 30 days after undergoing cardiac surgery via an open or endovascular approach at a major academic medical center in 2015-2017 were reviewed. LVOs were identified through review of imaging and medical records and their characteristics and clinical courses were examined.

Results Over the study period, 4,209 cardiac surgeries, including endovascular procedures, were performed. Of 111 patients classified as having stroke, 8 had LVO. Two of the three patients who received mechanical thrombectomy returned to independent living, compared to only 1 of the 5 patients who did not undergo thrombectomy. In the 2 weeks following cardiac surgery, the rate of LVO was estimated at $200 \mathrm{x}$ that of the general population.

Conclusion Of patients undergoing cardiac surgery at an academic medical center, $0.2 \%(95 \%$ CI $0.1-0.4 \%)$ had LVO within 30 days. Cardiac surgery patients and their caregivers should be counseled about the warning signs of stroke, the importance of timely intervention, and how to seek emergency care in the postoperative period.

Disclosures D. Wilkinson: None. S. Koduri: None. J. Burke: None. J. Gemmete: None. N. Chaudhary: None. H. Patel: None. A. Pandey: None.

\section{E-131 OUTCOMES OF MECHANICAL THROMBECTOMY FOR ACUTE ISCHEMIC STROKE IN NATIVE AMERICAN POPULATION: A PRELIMINARY STUDY}

${ }^{1} \mathrm{~A}$ lkram*, 'S Suriya, ${ }^{1} \mathrm{M}$ Farooqui, ${ }^{1} \mathrm{O}$ Owens, ${ }^{1} \mathrm{~A}$ Alvarado Arias, ${ }^{2} \mathrm{D}$ Sorte, ${ }^{3} \mathrm{~A}$ Carlson, ${ }^{4} \mathrm{~S}$ Ortega-Guiterrez, ${ }^{1} \mathrm{M}$ Torbey, ${ }^{1} \mathrm{~A}$ Zafar. ${ }^{1}$ Neurology, University of New Mexico Health Sciences Center, Albuquerque, NM; ${ }^{2}$ Neurourgeny, University of New Mexico Health Sciences Center, Albuquerque, NM; ${ }^{3}$ Neurosurgery, University of New Mexico Health Sciences Center, Albuquerque, NM; ${ }^{4}$ Neurology, University of lowa Hospital, lowa City, IA
Objectives The primary objective of this study is to evaluate the difference in the functional and neurological outcomes after mechanical thrombectomy (MT) for an acute ischemic stroke (AIS), between Native Americans (NA) patients versus other ethnicities.

Background There is scarcity of data regarding outcome of MT in NA population. Considering the dynamics of the state of New Mexico and a diverse patient population, we evaluated the difference in outcome between NA patients with comparison group representing other ethnicities.

Methods This is a preliminary, observational retrospective case-control study. All NA patients who underwent MT for LVO from January 01, 2016 to December 31, 2018 at UNMH were included. Data was extracted from Cerner database at UNMH and was collected on secured Redcap ${ }^{\mathrm{TM}}$ database. Patients were categorized into NA vs comparison group (other ethnicities) into two groups, with the ratio of $1: 4$ respectively.

Results A total of 35 patients who underwent MT at UNMH for an AIS were included in analysis: seven NA and 28 controls. Nine patients $(\mathrm{NA}=7)$ were directly admitted through ED while 26 were transferred from outside hospitals $(\mathrm{NA}=6)$. Prevalence of vascular risk factors, including Hypertension, hyperlipidemia, Coronary artery disease, Diabetes Mellitus was noticeably higher in NA than the comparison group. There was no statistical difference in the two groups with regards to median time interval from last known well (LKW) to groin puncture, and from LKW to reperfusion. The mortality was $14 \%$ in NA group and $4 \%$ in the comparison group. The median NIHSS on discharge between NA and comparison group was 13 and 15.5, respectively. The median mRS at 6 months follow up was 1 in NA and 2 in comparison group, however this was not statistically significant.

Abstract E-131 Table 1 Demographics and comorbidities of patients who underwent Mechanical Thrombectomy (MT)

\begin{tabular}{lll}
\hline & $\begin{array}{l}\text { Natives with MT } \\
(\mathrm{N}=7)\end{array}$ & $\begin{array}{l}\text { Comparison group with MT } \\
(\mathrm{N}=28)\end{array}$ \\
\hline Mean Age & 63 & 69 \\
Gender & $3(43 \%)$ & $13(46 \%)$ \\
- Female & $4(57 \%)$ & $15(53 \%)$ \\
- Male & & \\
Ethnicity & $0(0 \%)$ & $19(68 \%)$ \\
- Caucasian & $0(0 \%)$ & $1(4 \%)$ \\
- African & $0(0 \%)$ & $6(21 \%)$ \\
- Hispanic & $7(100 \%)$ & $0(0 \%)$ \\
- Native American & $0(0 \%)$ & $2(7 \%)$ \\
- Unknown & & \\
OSH Transfers & $6(86 \%)$ & $20(71 \%)$ \\
TPA given & $4(57 \%)$ & $18(62 \%)$ \\
Medical History & $6(86 \%)$ & $13(52 \%)$ \\
- HTN & $5(71 \%)$ & $4(14 \%)$ \\
- HLD & $2(29 \%)$ & $4(14 \%)$ \\
- CHF & $3(43 \%)$ & $2(7 \%)$ \\
- CAD & $0(0 \%)$ & $9(32 \%)$ \\
- AF & $3(43 \%)$ & $6(21 \%)$ \\
- DM & $2(29 \%)$ & $1(4 \%)$ \\
- Previous IS & $0(0 \%)$ & $0(0 \%)$ \\
- Previous HS & $2(29 \%)$ & $9(32 \%)$ \\
- Tobacco use & & \\
\hline & & \\
- & & \\
\hline
\end{tabular}

